\title{
VERBENACEAE J.ST.-HIL. DO PARQUE ESTADUAL DO IBITIPOCA, MINAS GERAIS, BRASIL
}

\author{
LUDYMILA VIANA VALADARES CRUZ \& FÁTIMA REGINA GONÇALVES SALIMENA
}

\author{
Departamento de Botânica, Instituto de Ciências Biológicas, Universidade Federal de \\ Juiz de Fora, Campus Universitário, 36036-900 - Juiz de Fora, MG, Brasil. \\ Autora para correspondência: ludymilacruz@hotmail.com
}

\begin{abstract}
Verbenaceae J.St.-Hil. from the State Park of Ibitipoca, Minas Gerais, Brazil). The Parque Estadual do lbitipoca (PEIB) is part of the Serra da Mantiqueira; it is located in the southeast of the Zona da Mata of Minas Gerais, and belongs to the Atlantic Domain, with predominance of campos rupestres (rocky grasslands) in a vegetational mosaic between altitudes of 1000 to $1784 \mathrm{~m}$. This paper presents the study of the Verbenaceae family from this area, where four genera and nine species were found: Lantana camara, L. fucata, Lippia hermannioides, L. Iupulina, L. origanoides, Stachytarpheta sellowiana, Verbena bonariensis, $V$. hirta $e V$. litoralis. Recent records of $L$. hermannioides and $S$. sellowiana were not found; their occurrence in the area is reported with collections that date back over 45 and 120 years, respectively. Stachytarpheta sellowiana have restrict occurrence to the South of Serra da Mantiqueira and is considered critically endangered.
\end{abstract}

Key words: Atlantic Forest, Campos rupestres, Mantiqueira Range, Lamiales.

Resumo - (Verbenaceae J.St.-Hil. do Parque Estadual do Ibitipoca, Minas Gerais, Brasil). O Parque Estadual do Ibitipoca (PEIB) faz parte do Complexo da Mantiqueira situado no sudeste da Zona da Mata Mineira e inserido no Domínio Atlântico, com predomínio dos campos rupestres, em altitudes entre 1000 e $1784 \mathrm{~m}$. Este trabalho apresenta o estudo da família Verbenaceae na área, onde foram encontrados quatro gêneros e nove espécies: Lantana camara, L. fucata, Lippia hermannioides, L. lupulina, L. origanoides, Stachytarpheta sellowiana, Verbena bonariensis, V. hirta e V. litoralis. Registros recentes de L. hermannioides e S. sellowiana não foram encontrados e as coleções destas espécies datam de mais de 45 e 120 anos de ocorrência na área, respectivamente. Stachytarpheta sellowiana é considerada criticamente ameaçada e com ocorrência restrita para a região Sul da Serra da Mantiqueira.

Palavras-chave: Campos rupestres, Floresta Atlântica, Serra da Mantiqueira, Lamiales.

\section{Introdução}

Verbenaceae J.St.-Hil. reune cerca de 1200 espécies e 35 gêneros (Marx et al. 2010, Atkins 2004) com distribuição nas regiões áridas e semiáridas das Américas, Andes e África (Olmstead 2012). Com base em estudos filogenéticos recentes, 50 gêneros tradicionalmente reconhecidos como pertencentes à Verbenaceae foram transferidos para Lamiaceae (Cantino et al. 1992). As inferências filogenéticas sugerem a origem da família na América do Sul, onde ocorre em uma ampla variedade de ecossistemas e um segundo centro de diversidade na África, relacionado a aproximadamente seis eventos independentes de colonização que originaram as espécies do Velho Mundo (Marx et al. 2010). No Brasil, ocorrem 16 gêneros e 286 espécies, sendo 187 endêmicas (BFG 2015) e 50 consideradas raras (Salimena et al. 2009). Os campos rupestres e cerrados apresentam a maior riqueza nos gêneros Lippia L. e Stachytarpheta Vahl e representam um dos centros de diversidade para estes gêneros (Salimena 2002, Atkins 2005).

Poucos são os estudos de Verbenaceae que incluem as espécies da flora brasileira, sendo o tratamento de Schauer (1847) o mais clássico e completo. Destacam-se as contribuições para as floras da Serra do Cipó (Salimena-Pires \& Giulietti 1998) e Grão Mogol (Salimena \& Silva 2009) no estado de Minas Gerais, Flora de Goiás e Tocantins (Salimena et al. 2016) e Flora do Distrito Federal (Salimena et al. 2015) na região centro-oeste.

O Parque Estadual do Ibitipoca (PEIB) é uma das Unidades de Conservação mais importantes do estado de Minas Gerais, sendo considerado uma das áreas prioritárias para conservação florística (Menini Neto \& Salimena 2013) e de importância biológica especial (Drummond et al. 2005). A região apresenta irregularidades topográficas e altitudinais que permitem a formação de um mosaico de paisagens e fitofisionomias, onde se desenvolve uma complexa e importante riqueza florística (Oliveira-Filho et al. 2013, Forzza et al. 2013). O PEIB atrai milhares de turistas anualmente por sua beleza rara e cênica, incluindo cavernas, paredões rochosos e várias cachoeiras, configurando-se como patrimônio natural vulnerável aos impactos da grande pressão antrópica advinda da visitação intensa (Menini Neto \& Salimena 2013).

O objetivo do presente estudo é apresentar o tratamento taxonômico da família Verbenaceae para o 
PEIB, contribuindo para o conhecimento florístico desta unidade de conservação e do estado de Minas Gerais.

\section{Material e Métodos}

Foram realizadas coletas mensais no PEIB entre março de 2014 e março de 2015, sendo o material coletado preparado segundo Fidalgo \& Bononi (1984) e depositado na coleção do Herbário Leopoldo Krieger (CESJ). As análises morfológicas e descrições das espécies foram baseadas nas coleções depositadas nos herbários BHCB, CESJ e RB (acrônimos segundo Thiers 2016) incluindo material adicional procedente de outras regiões, quando necessário. As descrições morfológicas seguem a terminologia de Harris \& Harris (2001). As ilustrações foram elaboradas com auxílio de câmara clara acoplada a microscópio estereoscópico Wild M10.

\section{Resultados e Discussão}

No Parque Estadual do Ibitipoca a família Verbenaceae está representada por quatro gêneros e nove espécies: Lantana camara L., L. fucata Lindl., Lippia hermannioides Cham., L. Iupulina Cham., L. origanoides Kunth, Stachytarpheta sellowiana Schauer, Verbena bonariensis L., V. hirta Spreng. e V. litoralis Kunth.
A citação do gênero Glandularia J. F. Gmel. para o PEIB (Forzza et al. 2013), não se confirmou no presente estudo. As coleções identificadas como Glandularia lobata (Vell.) P. Peralta \& Thode tratam-se de Verbena hirta, o que exclui a ocorrência do gênero Glandularia na área.

Lantana camara, Verbena bonariensis e $\mathrm{V}$. litoralis são consideradas espécies ruderais, seguindo as definições de Moro et al. (2012), ocorrendo em locais antropizados, que no PEIB fazem parte da paisagem de muitas áreas com grande fluxo de turistas, à beira de trilhas e no Centro de Visitantes. Da mesma forma foi registrada a ocorrência recente de Verbena bonariensis, espécie de ampla distribuição e considerada ruderal (O'Leary et al. 2007) encontrada próxima ao Centro de Visitantes do PEIB, o que vem apontando a necessidade de manejo da área.

Apesar de coletas sistemáticas ao longo dos últimos dez anos, Stachytarpheta sellowiana e Lippia hermannioides não foram encontradas recentemente na área, sendo os últimos registros datados de $45 \mathrm{e}$ 120 anos, respectivamente. Estas coleções fazem referências à "Serra do Ibitipoca", área mais ampla, podendo estar extintas localmente ou apresentarem ocorrência no entorno, sem ocorrência na área delimitada para o PEIB. Dada a incerteza, optou-se por incluir estas espécies neste estudo, pois a Serra da Mantiqueira representa o limite sul de ocorrência de $L$. hermannioides que é comum nos campos rupestres da Cadeia do Espinhaço, enquanto $S$. sellowiana é endêmica dos campos de altitude e campos rupestres da Mantiqueira, especialmente da região do Planalto do Alto Rio Grande.

\section{Chave para identificação das espécies de Verbenaceae do Parque Estadual do Ibitipoca}

1. Corola azul; 2 estames perfeitos, 2 estaminódios Stachytarpheta sellowiana

1'. Corola alva, rósea ou lilás; 4 estames perfeitos.

2. Fruto drupa

3. Ramos subtetragonais, aculeados, tricomas simples, tricomas glandulares presentes

3'. Ramos cilíndricos, inermes, tricomas simples, tricomas glandulares ausentes

Lantana

Fruto esquizocarpo

4. Corola zigomorfa; esquizocarpo com 2 mericarpos ................................................................................. Lippia

5. Inflorescências em espigas tetragonais, brácteas carenadas, dispostas em 4 séries, tetrásticas

5'. Inflorescências em espigas globosas, brácteas planas, imbricadas espiraladamente.

6. Folhas pecioladas, lâminas ovais, 4-6 × 3-4 cm; brácteas membranáceas róseas .......................... Lippia lupulina

6 '. Folhas subpecioladas, lâminas elípticas ou obovadas, $1-2 \times 0,5-1 \mathrm{~cm}$; brácteas

foliáceas verdes ............................................. Lippia hermannioides

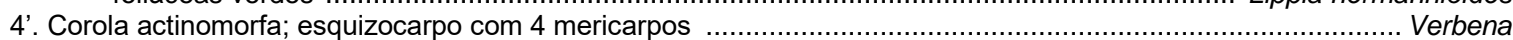

7. Inflorescências rígidas, congestas, corimbiformes, tubo da corola maior que $3 \mathrm{~mm}$ compr.

8. Base da lâmina foliar cuneada; fauce da corola com tricomas moniliformes

Verbena hirta

8'. Base da lâmina foliar auriculada; fauce da corola glabra

Verbena bonariensis

7'. Inflorescências filiformes, delgadas, paniculiformes; tubo da corola 2-3 mm compr. Verbena litoralis

\section{Lantana L.}

Arbusto ou subarbusto. Folhas decussadas ou 3-verticiladas; pecioladas ou subsésseis. Inflorescências terminais ou axilares, em racemos espiciformes ou capituliformes, alongadas ou não na frutificação, brácteas verdes, raro vináceas, foliáceas. Cálice membranáceo, truncado, 2-5-lobado persistente e acrescente ou não no fruto. Corola alva, rosa ou lilás, zigomorfa, hipocrateriforme, 2-labiada, lábio anterior 3-lobado, lábio posterior 2-lobado, tubo cilíndrico. Estames 4, perfeitos, inseridos na metade do tubo da corola, inclusos. Ovário 2-carpelar a 1- 
carpelar por aborto, carpelos 2-locular, lóculos uniovulados, estilete curto, terminal, estigma oblíquo. Fruto drupa.

Lantana reúne cerca de 150 espécies com distribuição tropical e subtropical com centro de diversidade no Brasil (Silva 1999, Atkins 2004), onde ocorre em todos os estados e domínios fitogeográficos, com 21 espécies, sendo 11 endêmicas (BFG 2015).

\subsection{Lantana camara L., Sp. PI.: 627. 1753.}

Fig. 1. A

Arbusto, 2-3 $\mathrm{m}$ alt., ramificado, ramos subtetragonais, aculeados, tricomas simples e glandulares. Folhas pecioladas, pecíolo 5-15 mm compr., lâmina 2,5-8 × 1,2-3,5 cm, membranácea, estreito-oval a largo-oval, ápice agudo a acuminado, margem serreada, base cordada, obtusa ou atenuada, face adaxial e abaxial hirsutas. Inflorescências axilares, espigas 1-2 por axila, 3-7 cm compr., brácteas verdes, foliáceas, estreito-ovais a oblongas, 4-7 × 1-1,5 mm, tricomas alvos, glandulares. Cálice 4lobado, ca. 2,5 mm compr., pubescente. Corola hipocrateriforme, lilás a rósea, tubo reto, ca. $1 \mathrm{~cm}$ compr. Estames 4 perfeitos, inseridos na metade do tubo da corola, didínamos. Ovário ca. 0,5 mm compr. Fruto ca. $5 \times 5 \mathrm{~mm}$, vináceo.

Material examinado: MINAS GERAIS. Lima Duarte, Conceição do Ibitipoca, Parque Estadual do Ibitipoca: $100 \mathrm{~m}$ da portaria, 9.XI.2015 (fl.), L.V.V. Cruz et al. 91 (CESJ); 28.XII.2015 (fl., fr.), L.V.V. Cruz et al. 98 (CESJ).

Lantana camara é a espécie com a mais ampla distribuição no gênero Lantana, sendo originalmente nativa da América tropical, ocorrendo atualmente em diferentes partes do mundo (Silva 1999). No Brasil, está presente em todos os estados, exceto Alagoas e Sergipe, principalmente nos domínios da Amazônia, Caatinga, Cerrado e Floresta Atlântica (BFG 2015). É considerada uma espécie ruderal, muito comum em áreas antropizadas (Moro et al. 2012) e no PEIB ocorre em áreas sob forte influência antrópica.

1.2. Lantana fucata Lindl., Bot. Reg. 10: t. 798. 1824.

Fig. 1. B-C

Arbusto, 0,7-1,5 $\mathrm{m}$ alt., ramificado, ramos cilíndricos, inermes, tricomas simples. Folhas pecioladas, pecíolo 2-15 mm compr., lâmina 1,5-6,5 × 0,7-3,5 cm, membranácea, elíptica, ápice agudo a atenuado, margem serreada, base subcordada a atenuada, face adaxial hirtela, face abaxial tormentosa. Inflorescências axilares, espigas 1 por axila, 1-2 cm compr., brácteas verdes, foliáceas, largoovais, 5-7,5 mm compr., tomentosas. Cálice 4-5lobado, 1-2 mm compr., tricomas simples. Corola hipocrateriforme, lilás a rósea, tubo reto, 0,6-1 mm compr. Estames inseridos na metade do tubo da corola, didínamos. Ovário ca. $0,4 \mathrm{~mm}$ compr. Fruto globoso, ca. 2,5 × $4 \mathrm{~mm}$, vináceo.

Material examinado: MINAS GERAIS. Lima Duarte, Conceição do Ibitipoca, Parque Estadual do Ibitipoca: 27.IV.1988 (fl.), P. Andrade et al. 1172 (BHCB, CESJ); entre o Monjolinho e a Lagoa Seca, 10.IV.2015 (fl.), L.V.V. Cruz et al. 1 (CESJ); 14.VIII.2015 (fl., fr.), L.V.V. Cruz et al. 63 (CESJ); 23.X.2015 (fl.), L.V.V. Cruz et al. 90 (CESJ); área de Camping, VII.1999 (fl.), M.A. Manhães 32 (CESJ); trilha entre a Lombada e o Cruzeiro, 11.III.2004 (fl.), R.C. Forzza et al. 3222 (RB,CESJ); trilha da Ponte de Pedra, 31.III.2004 (fl.), R.C. Forzza et al. 3303 (RB, CESJ); Monjolinho, 19.V.1991 (fl.), F.R.S. Pires \& M. Brugger, s.n., (CESJ 25962); 17.IV.1987 (fl.), L. Krieger (CESJ 21406).

Lantana fucata é amplamente distribuída nas regiões tropicais e subtropicais da América (Silva 1999). No Brasil, ocorre em parte das regiões Nordeste, Centro-oeste, Sudeste e Sul, nos domínios da Caatinga, Cerrado e Floresta Atlântica (BFG 2015). No PEIB, ocorre nas savanas arbustivo-arbórea nebular e arbustiva, campina lenhosa nebular e campina nebular.

\section{Lippia L.}

Erva, subarbusto ou arbusto. Folhas decussadas ou verticiladas, geralmente aromáticas, pecioladas ou sésseis. Inflorescências axilares em racemos capituliformes, brácteas verdes ou coloridas, foliáceas ou membranáceas. Cálice menor que as pétalas, membranáceo, 2-4 lobado. Corola alva, rósea, magenta ou amarela, zigomorfa, hipocrateriforme ou infundibuliforme, limbo 2-labiado, lábio anterior 3lobado. Estames 4 perfeitos, didínamos, inclusos. Ovário 2-carpelar, carpelo 2-locular, lóculos uniovulados basais, estilete reduzido, incluso, estigma oblíquo. Fruto esquizocarpo, separando-se em 2 mericarpos na maturidade.

Lippia apresenta aproximadamente 200 espécies, com ampla distribuição na região neotropical (Atkins 2004). No Brasil, ocorre em todos os estados, representado por 82 espécies, sendo 61 endêmicas, com maior riqueza nos cerrados e campos rupestres (BFG 2015). O gênero é morfologicamente similar a Lantana, diferindo principalmente por apresentar fruto esquizocárpico, enquanto em Lantana o fruto é do tipo drupa (Santos et al. 2009, Salimena 2010).

2.1. Lippia hermannioides Cham., Linnaea. 7: 219. 1832

Fig. 1.D, 2.A-D

Arbusto, 1-2 m alt., muito ramificado, ramos cilíndricos, tricomas glandulares capitados. Folhas subpecioladas, pecíolo ca. $1 \mathrm{~mm}$, lâmina 1-2 × 0,5-1 $\mathrm{cm}$, cartácea, sésseis, $2 \times 1 \mathrm{~cm}$ elíptica a obovada, ápice obtuso, retuso ou agudo, margem denteada, 

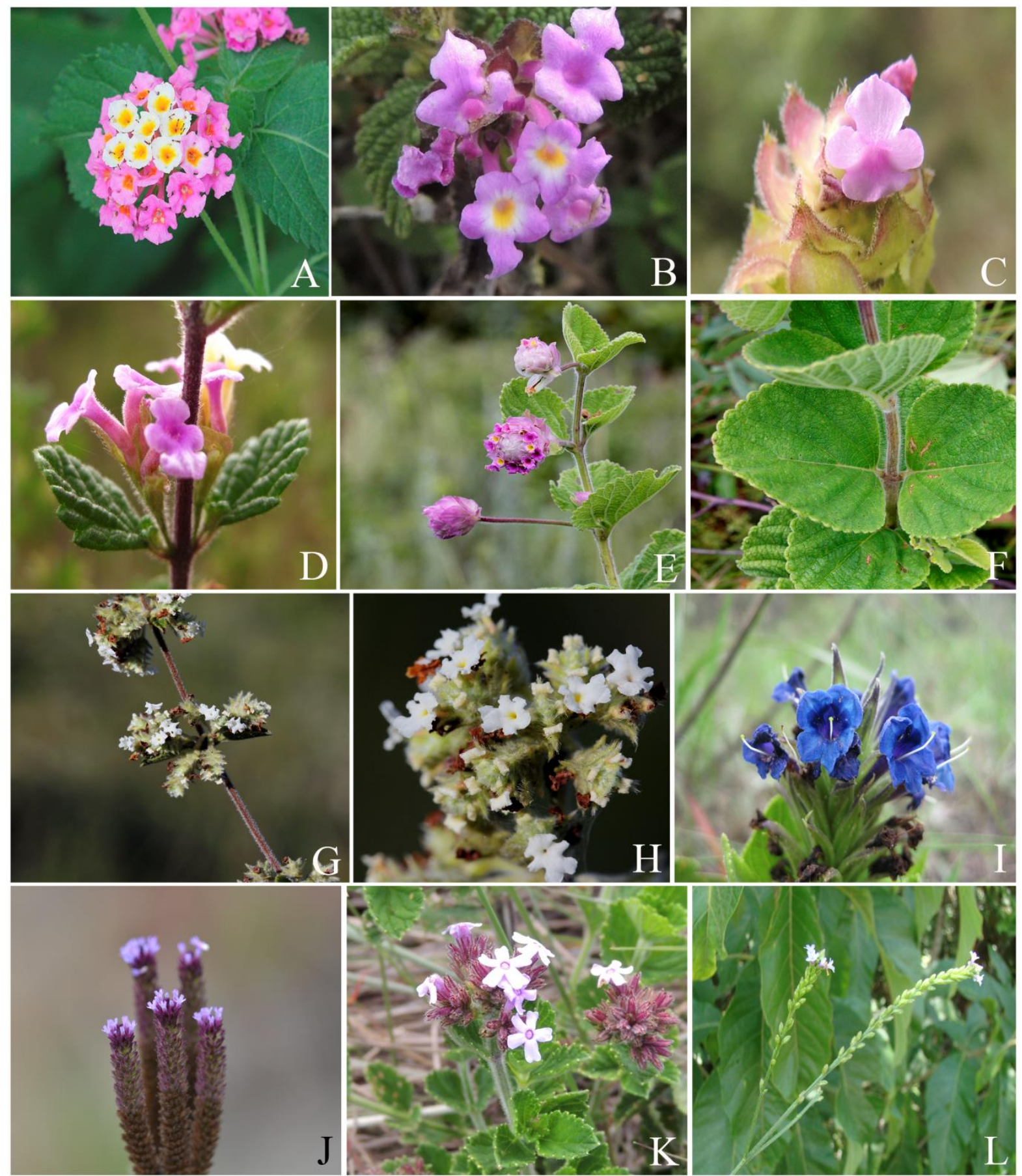

Fig. 1: A. Lantana camara; B e C. Lantana fucata; D. Lippia hermannioides; E e F. Lippia lupulina; G e H. Lippia origanoides; I. Stachytarpheta sellowiana; J. Verbena bonariensis, K. Verbena hirta; L. Verbena litoralis. Apenas fotografias de L. camara, L. fucata são procedentes do PEIB. Fotografias: Maurício Mercadante (A, E-H), Ludymila Viana V. Cruz (B e K); Thiago Rubioli da Fonseca (C); Vinícius Antônio de Oliveira Dittrich (D e I), Braz Cosenza (J) e Fátima Regina G. Salimena (L). 


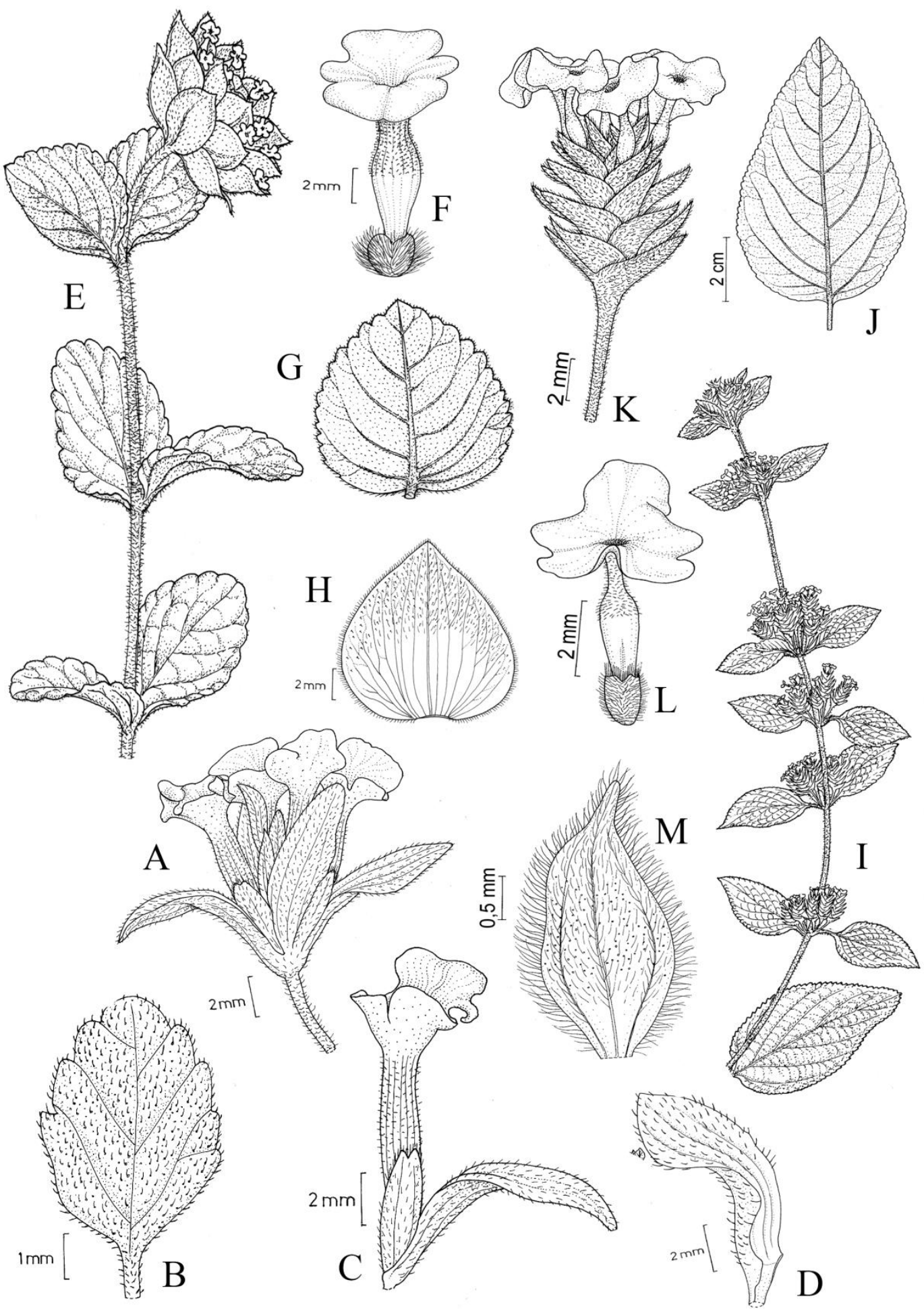

Fig. 2: A-D. Lippia hermannioides (F.A.Vitta \& V.C.Souza s.n. (SPF-CFSC 11752)). A. Inflorescência; B. Folha, face adaxial; C. Flor; D. Bráctea. E-H. Lippia lupulina (F.R.Salimena-Pires, S.A.P. Godoy \& V. Abbud s.n. (SPFCFSC 10715)): E. Ramo com inflorescência; F. Flor; G. Folha; H. Bráctea. I-M. Lippia origanoides (F.R.SalimenaPires \& V. C. Souza s.n. (SPF-CFSC 11417)): I. Ramo com inflorescências; J. Folha, face abaxial; K. Inflorescência; L. Flor; M. Bráctea. 
base atenuada, face adaxial escabra, face abaxial hirtela Inflorescências axilares solitárias, espigas globosas 1-4 floras, 1-1,5 cm compr., brácteas foliáceas, verdes, imbricadas, lanceoladas, 0,6-1 cm compr., tricomas curtos, simples. Cálice 2-lobado, $5 \times$ $1,5 \mathrm{~mm}$, tricomas glandulares. Corola hipocrateriforme, alva passando a rosa, magenta ou lilás, tubo reto, 7-8 $\mathrm{mm}$ compr. Estames 4 perfeitos, inseridos na metade do tubo da corola, didínamos. Ovário ca. $0,5 \mathrm{~mm}$ compr. Fruto obovoide, apiculado, $2 \times 1,5 \mathrm{~mm}$, mericarpos 2, frequentemente com apenas um desenvolvido, castanhos, lisos externamente.

Material examinado: MINAS GERAIS. Lima Duarte, Conceição do Ibitipoca, Serra do Ibitipoca, 11.VIII.1896 (fl.), W. Schwacke, s.n. (RB 12413).

Material adicional examinado: MINAS GERAIS. Santana do Riacho: Rodovia Belo Horizonte-Conceição do Mato Dentro, $\mathrm{km} \mathrm{114,} \mathrm{estrada} \mathrm{para} \mathrm{Usina} \mathrm{Dr.} \mathrm{Pacífico}$ Mascarenhas, 11.III.1990, F.A.Vita \& V.C.Souza s.n. (SPFCFSC 11752); Estrada Grão Mogol-Virgem da Lapa, 15.IV.1981 (fl.), I. Cordeiro et al., s.n., (CESJ 28650); Barão de Cocais, 26.III.2002 (fl.), A.M. Oliveira 63 (BHCB, CESJ); Caraça, 10.II.1987 (fl., fr.), M.B. Horta 52 (BHCB, CESJ).

Lippia hermannioides é endêmica do Brasil e se distribui pelos estados da Bahia, Distrito Federal, Goiás e Minas Gerais (BFG 2015), ocorrendo principalmente no Cerrado e Caatinga, sendo raros os registros para a Floresta Atlântica. $\mathrm{Na}$ área do PEIB, não foram encontrados registros recentes, com apenas uma coleção datada de 120 anos (Schwacke s.n. depositada no Herbário RB com número de tombo 12413), cuja referência no rótulo remete à "Serra do Ibitipoca", sem precisão do local de coleta. É possível que o local de ocorrência seja fora dos limites atuais da Unidade de Conservação ou que a espécie tenha sido extinta localmente.

2.2. Lippia Iupulina Cham., Linnaea 7: 222. 1832. Fig. 1. E-F, 2. E-H

Subarbusto, 0,3-0,8 m alt., ramificado, ramos subtetragonais, hirsutos, tricomas glandulares. Folhas subsésseis a pecioladas, pecíolo ca. $1 \mathrm{~cm}$ compr., lâmina 4-6 × 3-4 cm, coriácea, oval, ápice obtuso, margem serreada, base obtusa, face adaxial tomentosa-velutina a hirtela, face abaxial tomentosa. Inflorescências em espigas globosas, multifloras, 1,5-5 cm diâm.; brácteas, membranáceas, róseas, imbricadas, ovais, $1 \times 1 \mathrm{~cm}$., tricomas curtos, simples. Cálice 2-lobado, ca. $2 \mathrm{~mm}$ compr., tricomas glandulares externos. Corola hipocrateriforme, rosa, tubo curvo, 8-10 $\mathrm{mm}$ compr. Estames 4 perfeitos, inseridos na metade do tubo da corola, didínamos. Ovário ca. $2 \mathrm{~mm}$ compr. Fruto obovoide, ca. $3 \mathrm{~mm}$ compr., castanho, liso externamente.

Material examinado: MINAS GERAIS. Lima Duarte, Conceição do lbitipoca, Parque Estadual do Ibitipoca: 22.XI.2006 (fl.), R.C. Forzza et al., s.n., (RB 4355);
12.XI.1987 (fl.), H.C. Souza, s.n., (BHCB 15790); 27.IV.1988 (fl.), P. Andrade et al. 1172 (BHCB).

Material adicional examinado: MINAS GERAIS. Santana do Riacho: Rodovia Belo Horizonte-Conceição do Mato Dentro km 112: 9.X.1987 (fl.), F.R.Salimena-Pires, S.A.P. Godoy \& V. Abbud s.n. (SPF-CFSC 10715); Conceição do Ibitipoca: XI.2001 (fl.), F.R.G. Salimena \& P.H. Nobre 975 (CESJ).

Lippia lupulina está amplamente distribuída no Paraguai, Brasil e Argentina mais comumente nos cerrados (Salimena 2002). No Brasil, ocorre em parte das cinco regiões, nos domínios fitogeográficos da Amazônia, Cerrado e Floresta Atlântica (BFG 2015). No PEIB é encontrada em campina lenhosa nebular e campina nebular, destacando-se pelas inflorescências vistosas com brácteas róseas membranáceas.

2.3. Lippia origanoides Kunth, Nov. Gen. Sp. PI. 2: 267.1818.

Fig. 1. G-H, 2. I-M

Arbusto, 0,5-2 m alt., aromático, ramificado, ramos cilíndricos, hirsutas, tricomas simples. Folhas pecioladas, pecíolo ca. 2,5 mm compr., lâmina 6-15 × 4-14 mm, coriácea, oval-elíptica a suborbicular, ápice obtuso, margem crenada, base atenuada, face adaxial serícea a escabra, face abaxial tomentosa. Inflorescências em espigas tetragonais, 4-5 por axila, ca. $7 \mathrm{~mm}$ compr., brácteas foliáceas, verdes, carenadas, dispostas em 4 séries, ovais a ovallanceoladas, ca. $5 \mathrm{~mm}$ compr., tricomas longos, simples. Cálice 2-lobado, ca. $1 \mathrm{~mm}$ compr., tricomas glandulares externos. Corola hipocrateriforme, alva, raro rósea ou amarela, tubo reto, ca. $3 \mathrm{~mm}$ compr. Estames 4 perfeitos, inseridos na metade do tubo da corola, didínamos. Ovário ca. $0,5 \mathrm{~mm}$ compr. Fruto oblongo, $2 \times 1 \mathrm{~mm}$ compr., mericarpos 2 , castanhos, lisos externamente.

Material examinado: MINAS GERAIS. Lima Duarte, Conceição do Ibitipoca, Parque Estadual do Ibitipoca: 9.III.2006 (fl.), F.R.G. Salimena et al. 1342 (CESJ); entre as grutas do Fugitivo e Três Arcos, 11.III.2004 (fl.), R.C. Forzza et al. 3186 (CESJ, RB).

Material examinado adicional: MINAS GERAIS. Santana do Riacho; Rodovia Belo Horizonte-Conceição do Mato Dentro km 114, 15.IV.1980 (fl.), F.R.Salimena-Pires \& V.C.Souza s.n. (SPF-CFSC 11417). Lima Duarte, Conceição do Ibitipoca, Pedra do Gavião: 19.V.2001 (fl.), R.M. Castro et al. 339 (CESJ); arredores do Parque Estadual do Ibitipoca: 23.III.2002 (fl., fr.), F.S. Araújo \& A.S.M. Valente 194 (CESJ).

Lippia origanoides está amplamente distribuída na América do Sul, ocorrendo desde o sul dos Estados Unidos, México, Venezuela, Bolívia, Guiana, Paraguai, Brasil até o norte da Argentina (Moldenke 1965, Salimena-Pires \& Giulietti 1998, O'Leary et al. 2012). No Brasil, se distribui em parte das regiões Norte, Nordeste, Centro-Oeste e Sudeste, nos Domínios da Amazônia, Caatinga, Cerrado e Floresta Atlântica (BFG 2015), em solos pedregosos, de 160 a $1800 \mathrm{~m}$ de altitude. No PEIB, é encontrada 
em borda de nanofloresta nebular em altitudes acima de $1500 \mathrm{~m}$. Pode ser reconhecida pelas folhas aromáticas, inflorescências diminutas, reunidas em 4 a 5 por axila, brácteas dispostas em 4 séries e flores brancas.

\section{Stachytarpheta Vahl}

3.1. Stachytarpheta sellowiana Schauer in DC., Prodr. 11: 571. 1847.

Fig. 1. I

Subarbusto, ca. 0,6 m alt., ramificado, ramos cilíndricos, tricomas glandulares. Folhas sésseis, lâmina 2-5 × 1-2 cm, subpatente, coriácea, oboval, ápice obtuso, margem serrilhada, base atenuada, face adaxial e abaxial densamentes cobertas por tricomas simples e glandulares. Inflorescência robusta, congesta, espigas terminais 4-6 floras, $3-6 \times 3 \mathrm{~cm}$, brácteas verdes, estreito-ovais, ca. $8 \mathrm{~mm}$ compr., tricomas curtos, glandulares. Cálice 2-laciniado, ca. 14 $\mathrm{mm}$ compr., tricomas glandulares externos. Corola infundibuliforme, azul escuro, tubo ligeiramente curvo, ca. $15 \mathrm{~mm}$ compr. Estames 2 perfeitos, inseridos na metade do tubo da corola, estaminódios 2. Ovário ca. $2 \mathrm{~mm}$ compr. Fruto não visto.

Material examinado: MINAS GERAIS. Serra do Ibitipoca, 27.IX.1970 (fl.), Urbano \& L. Krieger (CESJ 9231).

Material adicional examinado: MINAS GERAIS. Lavras, Serra da Bocaina, Poço Bonito, 3.IV.1987 (fl.), D.A. Carvalho et al., s.n., (ESAL 6737, CESJ 46447); Serrinha, 15.XI.2001 (fl.), M.F. Vasconcelos 56 (BHCB, CESJ); Carrancas, 13.IV.1996 (fl.), F.R.S. Pires et al. 423 (CESJ); Lima Duarte, 14.XII.2005 (fl.), E. Tameirão Neto 3902 (CESJ/ BHCB).

Stachytarpheta sellowiana é endêmica do Brasil, restrita ao estado de Minas Gerais (BFG 2015). A espécie é considerada ameaçada, com populações restritas à região Sul da Serra da Mantiqueira (Atkins 2005). Foi encontrado apenas um registro para o PEIB, datado de mais de 45 anos, cuja coleção faz referência à "Serra do Ibitipoca". Uma vez que não há registros recentes na área, é possível que a espécie nunca tenha de fato ocorrido nos limites da Unidade de Conservação, com apenas ocorrências nos campos limpos do entorno ou tenha desaparecido localmente. Pode ser reconhecida por apresentar folhas obovais, subpatentes concentradas nos ápices dos ramos e flores de azul intenso.

\section{Verbena L.}

Erva ou subarbusto. Folhas decussadas, sésseis ou pecioladas. Inflorescências terminais, raro axilares, espiga simples ou em panículas, cilíndricas, congestas ou filiformes, laxas, brácteas verdes, foliáceas. Cálice, membranáceo, 5-laciniado. Corola branca, azul ou roxa, actinomorfa, hipocrateriforme ou infundibuliforme, 5-lobada, lobos desiguais. Estames 4, perfeitos, didínamos. Ovário 2-carpelar, carpelos 2locular, 1 óvulo por lóculo inserido na borda do carpelo, estilete reduzido, apical, estigma arredondado. Fruto esquizocarpo, separando-se em 4 mericarpos na maturidade.

O gênero Verbena reúne cerca de 200 a 250 espécies nas Américas tropical e temperada, com poucos representantes na Europa, Ásia e África (Atkins 2004). A maior diversidade de espécies ocorre na América do Sul, com táxons muito distintos dos encontrados na América do Norte ( $O$ ' Leary et al. 2007). No Brasil, ocorrem aproximadamente 16 espécies, sendo três endêmicas, distribuídas no Distrito Federal e nas regiões Sudeste e Sul, no Cerrado, Mata Atlântica e Pampa (BFG 2015).

\subsection{Verbena bonariensis L., Sp. PI. 1: 20. 1753.}

Fig. 1. J

Erva, ca. $0,8 \mathrm{~m}$ alt., ramos tetragonais, eretos, escabros, tricomas glandulares, principalmente nas arestas. Folhas sésseis, lâmina 3,5-6 × 0,7-1,2 $\mathrm{cm}$, cartácea, lanceolada, elíptico-ovada, ápice agudo, margem irregularmente serreada, base auriculada, face adaxial hirsuto-estrigosa, bulada, nervuras impressas; face abaxial hirsuto-escabra ao longo das nervuras proeminentes. Inflorescência terminal, densa, rígida, congesta, corimbiforme, 4-6,5 cm compr., as laterais nunca superando a principal; brácteas verdes, lanceoladas, 2-3 mm compr., hirsutas, margem ciliada. Cálice 5-laciniado, $2 \mathrm{~mm}$ compr., hirsuto-glanduloso, tricomas patentes, tricomas glandulares presentes ou não. Corola infundibuliforme, lilás, tubo cilíndrico, tubo da corola 4-5(-7) mm compr., superando o cálice, fauce glabra. Estames inseridos na metade superior do tubo da corola, conectivo superando as tecas. Ovário ca. 1 $\mathrm{mm}$ compr., glabro, oblongo. Fruto não visto.

Material examinado: MINAS GERAIS. Lima Duarte, Parque Estadual do Ibitipoca, 17.II.2017 (fl.), F.R.G. Salimena et al. 3978 (CESJ).

Material adicional examinado: MINAS GERAIS. Parque Nacional do Caparaó, 19.III.1988,(fl.), R.F.Novelino et al. s.n.(CESJ 22229).

Verbena bonariensis ocorre no noroeste e centro da Argentina, sul da Bolívia, Paraguai, Uruguai, sul e sudeste do Brasil (O'Leary et al. 2007), nos estados do Paraná, Rio Grande do Sul, Santa Catarina, Minas Gerais, Rio de Janeiro e São Paulo sobre os domínios da Floresta Atlântica e Pampa, sendo comum em áreas antropizadas, campos de altitude, campo limpo, florestas de galeria e florestas ombrófilas (BFG 2015). Em adição, este táxon foi introduzido em diversas áreas do mundo como América central e do norte, algumas regiões da Europa, África, Ásia, Austrália e Nova Zelândia (O'Leary et al. 2007). Ainda, de acordo com O'Leary et 
al. (2007) pode ser considerada invasora, as vezes agressiva e muito comum em solos modificados. No PEIB encontra-se na trilha para o centro de visitantes, área bastante perturbada pela passagem de turistas. Ilustrações em O'Leary et al. (2007).

4.2. Verbena hirta Spreng., Syst. Veg. 2: 749. 1825.

Fig. 1. K

Subarbusto, ca. $1 \mathrm{~m}$ alt., ramificado, ramos subtetragonais, decumbentes, hirsutos, tricomas simples. Folhas sésseis a subpecioladas, lâmina 0,5-4 $\times$ 0,2-3 cm, cartácea, oboval, raro oval, ápice agudo, margem revoluta, serreada no terço distal, base cuneada, face adaxial e abaxial densamente hirsuta. Inflorescência terminal, densa ou laxa, rígida, congesta, corimbiforme, 1,5-3 × 0,7-0,9 cm, as laterais nunca superando a principal, brácteas verdes, ovais, 2-6 mm compr., tricomas curtos, glandulares. Cálice 5laciniado, 3-5 × $3 \mathrm{~mm}$ comp., tricomas simples. Corola infundibuliforme, lilás, tubo reto, tubo da corola 4-8 $\times$ 1-1,5 mm, fauce com tricomas moniliformes. Estames inseridos na metade superior do tubo da corola. Ovário ca. $1 \mathrm{~mm}$ compr. Fruto oblongo, 2-2,5 × $1 \mathrm{~mm}$, mericarpos castanhos, reticulados externamente.

Material examinado: MINAS GERAIS. Lima Duarte, Serra do Ibitipoca, 19.IX.1940 (fl.), G.M. Magalhães 531 (NY,UB); Conceição do Ibitipoca, Serra do Ibitipoca: 30.IX.1970 (fl.), L. Krieger s.n. (CESJ 9231); Parque Estadual do Ibitipoca, 24.II.1977 (fl., fr.), M.P. Coons et al. 77-299 (VIC, CESJ); $21 . I .1987$ (fl.), H.C. Souza, s.n. (BHCB 15791); XII.2000 (fl.), F.R.G. Salimena, s.n., (CESJ 32688); Trilha do Monjolinho (Lagoa Seca), 30.III.2004 (fl.), B.R. Silva et al. 1306 (RB, CESJ); Caminho entre o Pico do Pião e a Cantina, 10.III.2004 (fl.), R.C. Forzza et al. 3125 (RB, CESJ); 23.Il.1992 (fl.), M. Eiterer \& G.S. Freitas 53 (CESJ); subida para a Janela do Céu, 10.IV.2015 (fl.), L.V.V. Cruz et al. 2 (CESJ).

Verbena hirta ocorre na Argentina e no Brasil, nos estados Rio Grande do Sul, Santa Catarina, Paraná e São Paulo (O' Leary et al. 2007), distribuição que foi ampliada para os estados de Minas Gerais e Rio de Janeiro, nos domínios do Cerrado, Floresta Atlântica e Pampa (BFG 2015). É comum nos campos de altitude e áreas antropizadas e no estado do Paraná é considerada invasora (O' Leary et al. 2007, BFG 2015). No PEIB é encontrada em savana arbustivo-arbórea nebular e savana arbustiva, campina lenhosa nebular e campina nebular. Pode ser reconhecida pelas folhas obovais, serreadas no terço distal, densamente hirsutas e flores lilases com tricomas moniliformes na fauce.

4.3 Verbena litoralis Kunth, Nov. Gen. Sp. 2: 276. 1817 [1818].

Fig. 1. L

Erva, ca. $0,8 \mathrm{~m}$ alt., ramificada, ramos tetragonais, eretos, tricomas simples. Folhas subsésseis a pecioladas, lâmina 1,5-7,5 × 0,5-1,5 cm, membranácea, elíptico-ovadas, oblongas ou obovada, ápice obtuso a agudo, cuneadas, margem irregularmente serreado-dentada, base ligeiramente subamplexicaule, auriculada, face adaxial e abaxial escabro-estrigosas ao longo das nervuras. Inflorescência terminal, delgada, filiforme, paniculiforme, 2-3 cm compr., as laterais superando a principal, brácteas verdes, ovais, $15-35 \mathrm{~mm}$ compr., margem ciliada, glabras na face adaxial. Cálice 5laciniado, 0,2-0,3 cm compr., tricomas simples. Corola infundibiliforme, roxa, lilás ou branca, tubo reto, tubo da corola 2-3 $\mathrm{mm}$ compr. Estames 4 perfeitos, inseridos na metade inferior do tubo da corola, didínamos. Ovário ca. $1 \mathrm{~mm}$ compr. Fruto oblongo, ca. 1,5 mm compr., mericarpos castanhos, reticulados externamente.

Material examinado: MINAS GERAIS. Lima Duarte, Conceição do Ibitipoca, Serra do Ibitipoca, Centro de Visitantes, 13.XII.2014 (fl.), B. Moreira et al. 80 (CESJ). Material adicional examinado: MINAS GERAIS. Viçosa, ESA: 19. VIII.1962 (fl., fr.), M.R.R. Vidal 180 (VIC, CESJ); Caeté, Serra da Piedade: $28 . I V .1985$ (fl.), L.H. Mundim, A.C. Pinto, T.S.M. Grandi, s.n. (CESJ 27066); 06.VI.1985 (fl.), J. Paula \& T.S.M. Grandi 1824 (CESJ).

Verbena litoralis é uma espécie amplamente distribuída, muito comum na América do Sul, desde o México até a Argentina (O' Leary et al. 2007). No Brasil ocorre nos estados de Minas Gerais, Rio de Janeiro, São Paulo, Paraná, Rio Grande do Sul e Santa Catarina, na Floresta Atlântica (BFG 2015). Considerada ruderal, segundo as definições de Moro et al. (2015), pode apresentar grande variação morfológica ao longo da área de distribuição (O'Leary et al. 2007). No PEIB, V. litoralis é encontrada em borda de nanofloresta nebular, próximo ao Centro de Visitantes, em área de grande fluxo de turistas. Como não existem registros mais antigos desta espécie na área, provavelmente sua presença esteja relacionada ao impacto antrópico recente.

\section{Agradecimentos}

Ao Programa de Pós-graduação em Ecologia da Universidade Federal de Juiz de Fora e ao IEF-MG, pelo apoio ao desenvolvimento deste trabalho e apoio logístico. Aos doutores Luiz Menini Neto e Berenice Chiavegatto Campos, pelas sugestões no texto.

\section{Referências}

ATKINS, S. 2004. Verbenaceae. In K. Kubtzki \& J.W. Kadereit (eds.). The families and genera of vascular plants. Springer. Berlin, vol. 7, p. 449-468.

ATKINS, S. 2005. The genus Stachytarpheta (Verbenaceae) in Brazil. Kew Bull. 60: 161-272. 
Verbenaceae J.St.-Hil. do Parque Estadual do Ibitipoca, Minas Gerais, Brasil

BFG - The Brazil Flora Group. 2015. Growing knowledge: an overview of seed plant diversity in Brazil. Rodriguésia 66(4): 1085-1113.

CANTINO, P.D. 1992. Evidence for a polyphyletic origin of Labiatae. Ann. Missouri Bot. Gard. 79: 361-379.

DRUMMOND, G.M., MARTINS, C.S., MACHADO, A.B.M., SEBAIO, F.A. \& ANTONINI, Y. 2005. Biodiversidade em Minas Gerais, um atlas para sua conservação. Fundação Biodiversitas. Belo Horizonte.

FIDALGO, O. \& BONONI, V.L.R. 1984. Técnicas de coleta, preservação e herborização de material botânico (Manual n.4). Instituto de Botânica. São Paulo.

FORZZA, R.C., MENINI NETO, L., SALIMENA, F.R.G. \& ZAPPI, D. 2013. Fanerógamas do Parque Estadual do Ibitipoca e suas relações florísticas com outras áreas com campo rupestre de Minas Gerais. In R.C. Forzza, L. Menini Neto, F.R.G. Salimena \& D. Zappi (eds.). Flora do Parque Estadual do Ibitipoca e seu entorno. Editora UFJF. Juiz de Fora, p.154-291.

HARRIS, J.G. \& HARRIS, M.W. 2001. Plant identification terminology: an illustrated glossary. Spring Lake Publishing. Spring Lake.

MARX, H., O'LEARY, N., YUAN, Y., LU-IRVING, P., TANK, D., MÚlGURA, M.E. \& OLMSTEAD, R. 2010. A molecular phylogeny and classification of Verbenaceae. Amer. J. Bot. 97: 1647-1663.

MENINI NETO, L. \& SALIMENA, F.R.G. 2013. História do Arraial de Conceição de Ibitipoca e criação do Parque Estadual do Ibitipoca. In R.C. Forzza, L. Menini Neto, F.R.G. Salimena \& D. Zappi (eds.). Flora do Parque Estadual do Ibitipoca e seu entorno. Editora UFJF. Juiz de Fora, p. 16-26.

MOLDENKE, H.N. 1965. Materials toward a monograph of the genus Lippia L. Phytologia 12: 67.

MORO, M.F., SOUZA, V.C., OLIVEIRA-FILHO, A.T., QUEIROZ, L.P., FRAGA, C.N., RODAL, M.J.N., ARAÚJO, F.S. \& MARTINS, F.R. 2012. Alienígenas na sala: o que fazer com espécies exóticas em trabalhos de taxonomia, florística e fitossociologia? Acta bot. bras. 26(4): 991-999.
OLIVEIRA-FILHO, A.T., FONTES, M.A.L., VIANA, P.L., VALENTE, A.S.M., SALIMENA, F.R.G. \& FERREIRA, F.M. 2013. O mosaico de fitofisionomias do Parque Estadual do Ibitipoca. In R.C. Forzza, L. Menini Neto, F.R.G. Salimena \& D. Zappi (eds.). Flora do Parque Estadual do Ibitipoca e seu entorno. Editora UFJF. Juiz de Fora, p. 53-94.

O'LEARY, N., DENHAN, S.S., SALIMENA, F.R.G. \& MÚLGURA, M.E. 2012. Species delimitation in Lippia section Goniostachyum (Verbenaceae) using the phylogenetic species concept. Bot. J. Linn. Soc.170: 197-219.

O'LEARY, N., MÚlguRA, M.E. \& MORRONE, O. 2007. Revisión taxonómica de las espécies del género Verbena (Verbenaceae): Serie Pachystachyae. Ann. Missouri Bot. Gard. 94: 571622.

OLMSTEAD, R.G. 2012. Phylogeny and biogeography in Solanaceae, Verbenaceae and Bignoniaceae: a comparison of continental and intercontinental diversification patterns. Bot. J. Linn. Soc. 171: 80-102.

SALIMENA-PIRES, F.R. \& GIULIETTI, A.M. 1998. Flora da Serra do Cipó, Minas Gerais: Verbenaceae. Bol. Bot. Univ. São Paulo 17: 155186.

SALIMENA, F.R.G. 2002. Novos sinônimos e tipificações em Lippia sect. Rhodolippia (Verbenaceae). Darwiniana 40: 1-4

SALIMENA, F.R.G. \& SILVA, T.R.S. 2009. Flora de Grão-Mogol, Minas Gerais: Verbenaceae. Bol. Bot. Univ. São Paulo 27: 119-126.

SALIMENA, F.R.G., FRANÇA, F. \& SILVA, T.R.S. 2009. Verbenaceae. In A.M. Giulietti, A. Rapini, M.J.G. Andrade, L.P. Queiroz \& J.M.C. Silva (orgs.). Plantas raras do Brasil. Editora Conservação Internacional. Belo Horizonte, p. 399-405.

SALIMENA, F.R.G. 2010. Uma nova espécie de Lippia L. (Verbenaceae) do cerrado brasileiro. Acta bot. bras. 24(1): 232-234.

SALIMENA, F.R.G., MÚlGURA, M.E. \& DIAS, A.M. 2015. Verbenaceae. In: T.B. Cavalcanti, A. P. Silva (orgs.) Flora do Distrito Federal. EMBRAPA. Brasília, DF.

SALIMENA, F.R.G., FERREIRA, S.C., CARDOSO, P.H., VALÉRIO \& V.I.R. 2016. Verbenaceae. In J.A. Rizzo (ed.). Flora dos Estados de Goiás e Tocantins. Coleção Rizzo. Universidade Federal de Goiás. Goiânia, vol. 47, p. 1-157. 
SANTOS, J.S., MELO, J.I.M., ABREU, M.C. \& SALES, M.F. 2009. Verbenaceae sensu stricto na região de Xingó: Alagoas e Sergipe, Brasil. Rodriguésia 60 (4): 985-998.

SCHAUER, J.C. 1847. Verbenaceae. In A.P. de Candolle (ed). Prodromus Systematis Naturalis Regni Vegetabilis. Victor Masson. Paris, vol. 11, p. 522-700.
SILVA, T.R.S. 1999. Redelimitação e revisão taxonômica do gênero Lantana L. (Verbenaceae) no Brasil. Tese de Doutorado, Universidade de São Paulo. São Paulo.

THIERS, B. 2016. A global directory of public herbaria and associated staff. New York Botanical Garden's Virtual Herbarium. Index Herbariorum. New York. Publish on internet: http://sweetgum.nybg.org/ science/ih/. (Acesso em 02/2016). 